\title{
MRAS gene marker rs 9818870 is not associated with acute coronary syndrome in the Czech population and does not predict mortality in males after acute coronary syndrome
}

\author{
Jaroslav A. Hubacek1, A, C, D, F, Vladimir Stanek 2, A, B, E, Marie Gebauerova ${ }^{2, A, B, E}$, Richard Ceska 3, A, B, E, \\ Vera Adamkova ${ }^{4, A, B, E}$, Vera Lanska ${ }^{5, A, C, E}$, Jan Pitha ${ }^{1, A-D, F}$ \\ ${ }^{1}$ Center for Experimental Medicine, Institute for Clinical and Experimental Medicine, Prague, Czech Republic \\ ${ }^{2}$ Cardiology Department, Institute for Clinical and Experimental Medicine, Prague, Czech Republic \\ ${ }^{3} 2^{\text {nd }}$ Department of Internal Medicine, General University Hospital, Prague, Czech Republic \\ ${ }^{4}$ Preventive Cardiology Department, Institute for Clinical and Experimental Medicine, Prague, Czech Republic \\ ${ }^{5}$ Statistical Unit, Institute for Clinical and Experimental Medicine, Prague, Czech Republic \\ A - research concept and design; $\mathrm{B}$ - collection and/or assembly of data; $\mathrm{C}$ - data analysis and interpretation; \\ $D$ - writing the article; $E$ - critical revision of the article; $F$ - final approval of the article
}

Address for correspondence

Jaroslav A. Hubacek

E-mail:jahb@ikem.cz

\section{Funding sources}

Project No. NT 12217-5 (Internal Grant Agency, Ministry of Health, (zech Republic) and the project for the development of research organization 00023001 (Institute for Clinical and Experimental Medicine, Prague, (zech Republic) - institutional support.

Conflict of interest

None declared

Received on January 19,2016

Reviewed on September 29, 2016

Accepted on December 1, 2016

\begin{abstract}
Background. Genome-wide association studies (GWAs) focused on cardiovascular diseases reveal variants within genes which have not been analyzed through the pre-GWAs era, and whose function is often unknown. One of them is variant r 59818870 at the MRAS gene locus.

Objectives. To analyze if MRAS polymorphism is associated with acute coronary syndrome (ACS) risk in a Czech population and with mortality in male patients after myocardial infarction.

Material and methods. 1,779 male patients with ACS (aged $55.3 \pm 7.9$ years) and 673 female patients with ACS (aged $64.0 \pm 8.1$ years) were genotyped for rs 9818870 polymorphism using the PCR-RFLP method. In a subset of 1,221 patients, detailed diagnoses (901 subjects with STEMI, 280 subjects with NSTEMI, 40 cases with unstable angina pectoris) were recorded. In 1,614 males, records about total and cardiovascular mortality were available.

Results. Whether the entire populations or males and females have been analyzed separately or not, we have not confirmed the described association between DNA marker rs9818870 and ACS in Czechs (30.4\% vs $29.4 \%$ carriers of the minor T allele [recessive model], $p=0.54 ; 0 \mathrm{R} 1.05 ; 95 \%$ Cl 0.89-1.24 for males and $32.1 \%$ vs $29.7 \%$ carriers of the minor $\mathrm{T}$ allele, $p=0.28 ; 0 \mathrm{R} 1.12 ; 95 \% \mathrm{Cl} 0.91-1.37$ for females $)$. Types of the ACS (STEMl and NSTEMI) or mortality (in males only) were not associated with the analyzed polymorphism (all $p>0.34)$.
\end{abstract}

Conclusions. The rs 9818870 variant is not associated with ACS or mortality in ACS patients in the Czech Slavonic population.

Key words: polymorphism, myocardial infarction, mortality, MRAS, Slavs

DOI

$10.17219 /$ acem $/ 67460$

Copyright

Copyright by Author(s)

This is an article distributed under the terms of the

Creative Commons Attribution Non-Commercial License

(http://creativecommons.org/licenses/by-nc-nd/4.0/) 


\section{Introduction}

Cardiovascular disease (CVD) and especially acute coronary syndrome (ACS) is among the most common mortality causes in developed countries. However, a substantial proportion of patients do not exhibit traditional CVD risk factors. Genetic polymorphisms could be used to better identify subjects at elevated risk of cardiovascular events. ${ }^{1}$

Interestingly, the risk associated with DNA variants detected by GWA (genome-wide association) studies is often partially (FTO) or even completely (9p21 locus) independent of "traditional" risk factors (smoking, diabetes, dyslipidemia). ${ }^{2-5}$

One of the CVD susceptibility loci has been discovered at the MRAS gene (muscle RAS oncogene homologgene, OMIM 608435, chromosomal location 3q22.3). The product of this gene is a protein, which is a member of the membrane-associated family of Ras GTPase proteins, mostly involved in cell growth and differentiation. ${ }^{6}$ These proteins play an important role in the TNF-alpha and MAP kinase-signaling pathways, which suggests that they may be involved in adhesion signaling. ${ }^{7}$ Finally, very high expression of MRAS has been detected in heart tissue, which supports the hypothesis that this protein plays a significant role in cardiovascular function. However, the role of MRAS in potential cardiovascular disease development remains unclear in detail.

Two independent GWA studies have associated the single nucleotide polymorphism rs9818870 (which clusters with 3 additional SNPs) with slightly (odds ratio of about 1.15) but significantly elevated risk of CAD. ${ }^{8,9}$ In both studies, interestingly, polymorphisms at this locus were not associated with traditional risk factors. ${ }^{89}$ Further, an association between the same locus and coronary arterial calcification was described, and Ellis et al. identified rs9818870 as a CAD risk predictor in individuals without apparent heart disease from the pooled sample of the Coronary Disease Cohort Study (CDCS), Canterbury Healthy Volunteer study (HV) and PostMyocardial Infarction study (PMI). ${ }^{910}$ Finally, a study of angiographed Saudi individuals suggests an association between the rs9818870 polymorphism and coronary artery disease, defined as narrowing of the coronary vessels by at least $50 \%{ }^{11}$

We attempted to determine whether the rs 9818870 variant at the MRAS locus would be associated with risk of ACS in the Czech Slavonic population, since, based on previous reports, the rs9818870 variant at the MRAS locus seems to be responsible for enhanced risk of coronary disease. To extend the current knowledge, we analyzed the connection between the same variant and allcause and cardiovascular mortality in a male subsample.

\section{Material and methods}

In our study, 1,779 male patients with ACS aged under 65 years ( $55.3 \pm 7.9$ years) and 673 female patients with ACS aged under 70 years (64.0 \pm 8.1 years) were included. ${ }^{12,13,15}$ They were consecutively enrolled between April 2006 and February 2015 at the Cardiology Unit of the Institute for Clinical and Experimental Medicine, Prague. In a subset of 1,221 patients, detailed diagnoses were recorded. The diagnoses were: 901 subjects with STEMI (722 males and 179 females), 280 subjects with NSTEMI (225 males and 55 females) and 40 cases with unstable angina pectoris.

Genotypes from 1,159 males ( $49.0 \pm 10.7$ years) and 1,344 females (48.6 \pm 10.6 years) were calculated as controls. These individuals were selected according to the WHO MONICA Project protocol as a $1 \%$ general population sample from 9 different Czech districts. ${ }^{15,16}$

Mortality data (3-8 years after ACS) for males was obtained from the Institute of Health Information and Statistics (under the Ministry of Health of the Czech Republic), where all death certificates of the Czech population are registered and analyzed. In our study we analyzed "all-cause mortality" and "cardiovascular mortality".

DNA was isolated from white blood cells using the "salting out" method with slight modifications. ${ }^{17}$ Rs9818870 was analyzed using a PCR-RFLP using the oligonucleotides 5' ttactttgacgtgtcagtgtatac and 5' tcagaccgtatgggttaagttctctgc and the Eco105I restriction enzyme. Restriction fragments were separated on 10\% PAA gel using the MADGE system. ${ }^{18}$ All chemicals (Taq DNA polymerase, PCR chemicals, dNTP) were purchased from Fermentas, Burlington (Ontario, Canada). From the first 500 analyzed subjects, $40 \mathrm{CC}, 5 \mathrm{CT}$ and $5 \mathrm{TT}$ subjects were sequenced to confirm the accuracy of the PCR-RFLP. One plate (94 samples) was genotyped twice by a different technician with $100 \%$ conformity. Within each plate, 1 standard sample was genotyped to ensure complete digestion. The accuracy of PCR-RFLP is similar to other methods used for genotyping. ${ }^{19}$

Lipoprotein parameters (determined in plasma after $12 \mathrm{~h}$ fasting in controls only) were measured using conventional enzymatic methods in a CDC Atlanta-accredited laboratory with a Roche COBAS MIRA autoanalyzer using Roche chemicals.

For controls, diastolic and systolic blood pressure was measured after $10 \mathrm{~min}$ resting in a seated position as an average of 3 readings on the right arm using an automated BP-203 (Nippon Colin Co., Ltd., Kobe, Japan) sphygmomanometer. The mean of the last 2 measurements was used for analysis. In ACS patients, because of acute settings during examination, only a history of self-reported hypertension (including the medication - use of antihypertensive drugs) was recorded. Similarly, the BMIs of patients were also calculated from selfreported data.

For control subjects, definitions of the risk factors were as follows: (1) self-reported past or current smoking; (2) dyslipidemia as total-cholesterol $>5.2 \mathrm{mmol} / \mathrm{L}$ and/or triglycerides $>2 \mathrm{mmol} / \mathrm{L}$ and/or self-reported use of lipid-lowering drugs; (3) body mass index (BMI) $\geq 30 \mathrm{~kg} / \mathrm{m}^{2}$; 
(4) hypertension (systolic/diastolic blood pressure higher than 139/89 mm Hg (measured in control group only) and/or self-reported use of antihypertensive drugs and (5) diabetes as fasting glucose over $7 \mathrm{mmol} / \mathrm{L}$ and/ or self-reported diabetes and/or antidiabetic medication. The self-reported information was obtained through selfcompleted personal questionnaires under the supervision of a trained nurse.

The Hardy-Weinberg equilibrium test [Court $\mathrm{MH}$ (2005-2008) Court-laboratory Hardy-Weinberg calculator http://www.tufts.edu/ mcourt01/Documents/ Court\%20lab\%20-\%20HW\%20calculator.xls (accessed November 2015)] was used to confirm the independent segregation of alleles. The $X^{2}$ tests [Tools of Science, http://www.physics.csbsju.edu/cgi-bin/stats/contingency_form.sh?nrow $=2 \&$ ncolumn $=3$ (accessed November 2015)] and odds ratios (95\% CI) [Hutchon DJR, (31/3/2001) http://www.physics.csbsju.edu/cgi-bin/stats/

Table 1. Basic characteristics of the groups and subgroups analyzed

\begin{tabular}{|c|c|c|c|c|}
\hline \multirow{2}{*}{ Characteristics } & \multicolumn{2}{|c|}{ Controls } & \multicolumn{2}{|c|}{ Patients } \\
\hline & males & females & males & females \\
\hline Number & 1,159 & 1,344 & 1,754 & 661 \\
\hline Age (years) & $49.0 \pm 10.8$ & $48.6 \pm 10.6$ & $55.3 \pm 7.9$ & $64.0 \pm 8.1$ \\
\hline $\begin{array}{l}\text { Total cholesterol } \\
(\mathrm{mmol} / \mathrm{L})\end{array}$ & $5.74 \pm 1.07$ & $5.81 \pm 1.14$ & $5.09 \pm 1.21$ & $5.38 \pm 1.19$ \\
\hline $\begin{array}{l}\text { Triglycerides } \\
\text { (mmol/L) }\end{array}$ & $1.96 \pm 1.30$ & $1.47 \pm 0.84$ & $2.03 \pm 1.65$ & $1.72 \pm 1.18$ \\
\hline $\mathrm{BMI}\left(\mathrm{kg} / \mathrm{m}^{2}\right)$ & $28.2 \pm 4.0$ & $27.6 \pm 5.5$ & $28.6 \pm 4.6$ & $28.8 \pm 5.6$ \\
\hline Non smokers (\%) & 41.3 & 63.8 & 22.9 & 35.8 \\
\hline T2DM (\%) & 8.9 & 6.8 & 17.4 & 18.9 \\
\hline Hypertension (\%) & 40.7 & 33.1 & 46.5 & 48.3 \\
\hline
\end{tabular}

Table 2. Frequencies of the rs9818870 genotypes in controls and acute coronary syndrome (ACS) patients

\begin{tabular}{|c|c|c|c|c|c|c|c|}
\hline \multirow{2}{*}{ Population } & \multicolumn{2}{|c|}{ Controls } & \multicolumn{2}{|c|}{ ACS patients } & OR $(95 \% \mathrm{Cl})$ & \multirow{2}{*}{ p-value } & \multirow{2}{*}{$p$-value* } \\
\hline & $\mathrm{n}$ & $\%$ & $\mathrm{n}$ & $\%$ & crude & & \\
\hline CC & 1764 & 70.5 & 1670 & 69.2 & & & $0.42^{\#}$ \\
\hline $\mathrm{CT}$ & 672 & 26.9 & 689 & 27.4 & $1.08(0.96-1.23)$ & 0.21 & $0.33^{\dagger}$ \\
\hline TT & 67 & 2.7 & 56 & 2.3 & $0.88(0.62-1.24)$ & 0.50 & $0.23^{\ddagger}$ \\
\hline \multirow{2}{*}{ Males } & \multicolumn{2}{|c|}{ Controls } & \multicolumn{2}{|c|}{ ACS patients } & OR $(95 \% \mathrm{Cl})$ & \multirow{2}{*}{$p$-value } & \multirow{2}{*}{$p$-value ${ }^{*}$} \\
\hline & $n$ & $\%$ & $n$ & $\%$ & crude & & \\
\hline CC & 819 & 70.7 & 1221 & 69.6 & & & $0.54^{\#}$ \\
\hline$C T$ & 308 & 26.6 & 491 & 28.0 & $1.07(0.90-1.26)$ & 0.43 & $0.61^{\dagger}$ \\
\hline TT & 32 & 2.8 & 42 & 2.4 & $0.88(0.55-1.41)$ & 0.59 & $0.54^{\ddagger}$ \\
\hline \multirow{2}{*}{ Females } & \multicolumn{2}{|c|}{ Controls } & \multicolumn{2}{|c|}{ ACS patients } & OR $(95 \% \mathrm{Cl})$ & \multirow{2}{*}{$p$-value } & \multirow{2}{*}{$p$-value* } \\
\hline & $\mathrm{n}$ & $\%$ & $n$ & $\%$ & crude & & \\
\hline CC & 945 & 70.3 & 449 & 67.9 & & & $0.51^{\#}$ \\
\hline $\mathrm{CT}$ & 364 & 27.1 & 198 & 30.0 & $1.14(0.93-1.41)$ & 0.20 & $0.35^{\dagger}$ \\
\hline $\mathrm{TT}$ & 35 & 2.6 & 14 & 2.1 & $0.84(0.45-1.58)$ & 0.59 & $0.28^{\ddagger}$ \\
\hline
\end{tabular}

p-values* for dominant ${ }^{\#}$, codominant ${ }^{\dagger}$ and recessive ${ }^{\ddagger}$ models of analysis are given. Results remain nonsignificant after adjustment for potential confounding variables (sex, age, smoking status, diabetes mellitus, hypertension, dyslipidemia and obesity). contingency_form.sh?nrow $=2 \&$ ncolumn $=3$ (accessed November 2015)] were calculated. Logistic regression (JMP Statistical Software, SIS Institute, Cary, USA) was used for the adjustment of OR with respect to potential confounding variables (sex, age, smoking status, diabetes mellitus, hypertension, dyslipidemia and obesity). P-values below 0.05 were considered significant.

\section{Results}

As expected, the patients were significantly older than controls $(p<0.001)$. All basic characteristics of controls and patients are summarized in Table 1.

There were no significant differences between the STEMI and NSTEMI groups with regard to the prevalence of traditional risk factors (data not shown in detail).

The frequencies of individual genotypes (Table 2) were in agreement with the Hardy-Weinberg equilibrium ( $\mathrm{p}=0.75$ for controls and $\mathrm{p}=0.13$ for patients). The minor allele frequency was almost identical to frequencies described in Western populations ( 0.15 in Western Europeans, 0.16 in Czechs). ${ }^{8,9}$

We did not confirm an association between the ACS and rs 9818870 polymorphism $(30.4 \%$ vs $29.4 \%$ of the minor $\mathrm{T}$ allele carriers [recessive model], $\mathrm{p}=0.54$; OR 1.05; 95\% CI $0.89-1.24$ for males and $32.1 \%$ vs $29.7 \%$ carriers of the $\mathrm{T}$ allele [recessive model], $\mathrm{p}=0.28$; OR 1.12; $95 \%$ CI $0.91-1.37$ for females). No significant association was found when males and females were analyzed together (Table 2). Adjusting for potentially confounding factors did not change these results significantly.

Similarly, no significant results were obtained when dominant (TT homozygotes vs $\mathrm{C}$ allele carriers; $\mathrm{p}=0.54$ and 0.45 ) and codominant (TT vs CT vs CC; $\mathrm{p}=0.61$ and 0.35 ) models were used. Also, the number of alleles did not significantly differ between the patients and controls ( $\mathrm{p}=0.73$ for females and 0.45 for males).

The genotypes distributions of the MRAS rs9818870 variant for STEMI and NSTEMI patients are shown in Table 3. Due to the low numbers, patients with unstable angina pectoris were not analyzed. No significant differences between the STEMI and NSTEMI groups were observed, regardless of the model of analysis used and irrespective of whether the entire population was compared, or males and females separately. 
In a subset of males with known genotypes $(\mathrm{n}=1,614$; 91.5\%), total and cardiovascular mortality were analyzed (Table 4). The distribution of rs9818870 genotypes was almost identical when survivors were compared with all-cause mortality cases $(30.5 \%$ vs $31.3 \%$ of the $\mathrm{T}$ allele carriers [recessive model], $\mathrm{p}=0.79$; OR 1.03 ; 95\% CI $0.74-$ $1.44)$ and CVD mortality cases $(30.5 \%$ vs $28.5 \%$ carriers of the minor $\mathrm{T}$ allele [recessive model], $\mathrm{p}=0.88$; OR 0.87 ; 95\% CI 0.56-1.39).

Similarly to the original GWA studies, we did not detect significant associations between the traditional ACS risk factors and rs9818870 polymorphism in the control males or females (dyslipidemia, hypertension, obesity, smoking and diabetes mellitus type 2 prevalence, all $\mathrm{p}>0.25$, results not shown in detail). ${ }^{8,9}$

Table 3. Frequencies of rs 9818870 genotypes in acute coronary syndrome (ACS) patients according the STEMI and NSTEMI diagnosis

\begin{tabular}{|c|c|c|c|c|c|}
\hline \multirow{2}{*}{ Population } & \multicolumn{2}{|c|}{ STEMI } & \multicolumn{2}{|c|}{ NSTEMI } & \multirow{2}{*}{$p$-value* } \\
\hline & $\mathrm{n}$ & $\%$ & $\mathrm{n}$ & $\%$ & \\
\hline CC & 619 & 68.7 & 200 & 71.4 & $0.39^{\#}$ \\
\hline CT & 264 & 29.3 & 74 & 26.4 & $0.65^{\dagger}$ \\
\hline TT & 18 & 2.1 & 6 & 2.1 & $0.88^{\ddagger}$ \\
\hline \multirow{2}{*}{ Males } & \multicolumn{2}{|c|}{ STEMI } & \multicolumn{2}{|c|}{ NSTEMI } & \multirow{2}{*}{$p$-value ${ }^{*}$} \\
\hline & $n$ & $\%$ & $n$ & $\%$ & \\
\hline CC & 499 & 69.1 & 163 & 72.4 & $0.34^{\#}$ \\
\hline $\mathrm{CT}$ & 209 & 28.9 & 57 & 25.3 & $0.57^{\dagger}$ \\
\hline TT & 14 & 1.9 & 5 & 2.2 & $0.79^{\ddagger}$ \\
\hline \multirow{2}{*}{ Females } & \multicolumn{2}{|c|}{ STEMI } & \multicolumn{2}{|c|}{ NSTEMI } & \multirow{2}{*}{$p$-value ${ }^{*}$} \\
\hline & $\mathrm{n}$ & $\%$ & $\mathrm{n}$ & $\%$ & \\
\hline CC & 120 & 67.0 & 37 & 67.3 & $0.97^{\#}$ \\
\hline $\mathrm{CT}$ & 55 & 30.7 & 17 & 30.9 & $0.98^{\dagger}$ \\
\hline TT & 4 & 2.2 & 1 & 1.8 & $\mathrm{na}{ }^{\ddagger}$ \\
\hline
\end{tabular}

p-values ${ }^{*}$ for dominant ${ }^{\#}$, codominant ${ }^{\dagger}$ and recessive ${ }^{\ddagger}$ models of analysis are given. Results remain nonsignificant after adjustment for potential confounding variables (sex, age, smoking status, diabetes mellitus, hypertension, dyslipidemia and obesity).

\section{Discussion}

In contrast to other SNPs detected by GWAs as associated with CVD, such as markers on chromosome 9, within the gene for sortilin or PCSK9, the MRAS locus has attracted far less attention, and only a few studies have been published. Given that the effect of the MRAS locus has an OR of approx. 1.10-1.15, some publication bias must be expected since only positive results have been published so far. ${ }^{13,20,21-23}$

Four studies, with quite different designs, suggested a possible, but weak, association between the rs 9818870 polymorphism at the MRAS locus and CVD risk. ${ }^{8-11}$

In comparison with these studies, we failed to detect this polymorphism as a risk for ACS development in the Czech-Slavonic population. Furthermore, no effect was observed regardless of whether patients with a STEMI or NSTEMI diagnosis were analyzed. The reasons for these contradictions are a subject of speculation. Three studies have been performed in Western European Caucasians (and the $4^{\text {th }}$ on Saudi-Arabians), which possibly indicates some differences both in genetic background and/or lifestyle. ${ }^{8-11}$ Furthermore, previous studies have focused on different outcomes, e.g., arterial calcification or angiographically-proven atherosclerosis, which is in contrast to our study, which includes cases with clinically manifested atherosclerosis. The number of analyzed individuals is not an issue, as it is similar in our and other original studies. ${ }^{8,9}$

Our study is the first to search for a potential association between the rs9818870 MRAS polymorphism and total ACS or cardiovascular mortality in males after ACS. In this case, the results were negative. We did not perform this analysis for females, because of the low power of the study in this case (the lower number of subjects analyzed and lower mortality compared to males).

As the rs9818870 variant is not associated with any traditional risk factors of atherosclerosis (a finding we have confirmed), the mechanism potentially leading to CVD development is still unclear. It is known that MRAS is expressed in the heart. Haas et al. speculate that rs9818870 may affect the expression of 2 regulatory microRNA (miRNA) molecules, namely miRNA-195 and miRNA-135, since they are located in close proximity to each other. ${ }^{24}$ It has been reported that miRNA-195 (located 16 to 38 nucleotides upstream of rs9818870) is expressed slightly higher in a failing human heart suffering from ventricular hypertrophy, which indicates that it may have some role in cardiac cell metabolism and development. $^{25}$ p-values* for dominant ${ }^{\#}$, codominant ${ }^{\dagger}$ and recessive ${ }^{\ddagger}$ models of analysis are given. Results remain nonsignificant after adjustment for potential confounding variables (sex, age, smoking status, diabetes mellitus, hypertension, dyslipidemia and obesity). acute coronary syndrome (ACS)

\begin{tabular}{|c|c|c|c|c|c|c|c|}
\hline \multirow{2}{*}{$\begin{array}{c}\text { Total } \\
\text { mortality }\end{array}$} & \multicolumn{2}{|c|}{ Survivors } & \multicolumn{2}{|c|}{ Nonsurvivors } & OR $(95 \% \mathrm{CI})$ & \multirow{2}{*}{$\mathrm{p}$-value } & \multirow{2}{*}{$p$-value* } \\
\hline & $\mathrm{n}$ & $\%$ & $\mathrm{n}$ & $\%$ & crude & & \\
\hline $\mathrm{CC}$ & 995 & 69.5 & 126 & 68.8 & & & $0.79^{\#}$ \\
\hline СТ & 400 & 28.0 & 53 & 28.7 & $1.04(0.74-1.47)$ & 0.80 & $0.93^{\dagger}$ \\
\hline TT & 36 & 2.5 & 4 & 2.6 & $0.88(0.31-2.51)$ & 0.81 & $0.85^{\ddagger}$ \\
\hline \multirow{2}{*}{$\begin{array}{c}\text { CVD } \\
\text { mortality }\end{array}$} & \multicolumn{2}{|c|}{ Survivors } & \multicolumn{2}{|c|}{ Nonsurvivors } & OR $(95 \% \mathrm{Cl})$ & \multirow{2}{*}{$p$-value } & \multirow{2}{*}{ p-value* } \\
\hline & $\mathrm{n}$ & $\%$ & $\mathrm{n}$ & $\%$ & crude & & \\
\hline CC & 995 & 69.5 & 79 & 72.5 & & & $0.88^{\#}$ \\
\hline CT & 400 & 28.0 & 27 & 24.8 & $0.85(0.54-1.34)$ & 0.48 & $0.77^{+}$ \\
\hline TT & 36 & 2.5 & 3 & 2.7 & $1.05(0.32-3.48)$ & 0.94 & $0.52^{\ddagger}$ \\
\hline
\end{tabular}


In summary, we did not confirm an association between acute coronary syndrome and the rs 9818870 polymorphism on chromosome 3 (3q22.3) in Czech-Slavonic males or females. Furthermore, we did not detect an association between this DNA marker and total ACS or cardiovascular mortality in male ACS survivors.

\section{References}

1. Kessler T, Schunkert H. Clinical validation of genetic markers for improved risk estimation. Eur J Prev Cardiol. 2012;19(2)(Suppl):25-32.

2. Liu C, Mou S, Pan C. The FTO gene rs9939609 polymorphism predicts risk of cardiovascular disease: A systematic review and metaanalysis. PLoS One. 2013;8:e71901.

3. Gustavsson J, Mehlig K, Leander K, et al. FTO genotype, physical activity, and coronary heart disease risk in Swedish men and women. Circ Cardiovasc Genet. 2014;7:171-177.

4. Hamsten A, Eriksson P. Quest for genes and mechanisms linking the human chromosome 9p21.3 locus to cardiovascular disease. Circulation. 2012;126:1815-1817.

5. Roberts R, Stewart AF. 9p21 and the genetic revolution for coronary artery disease. Clin Chem. 2012;58:104-112.

6. Kerkhoff E, Rapp UR. The Ras-Raf relationship: An unfinished puzzle. Adv Enzyme Regul. 2001;41:261-267.

7. Galkina E, Ley K. Vascular adhesion molecules in atherosclerosis. Arterioscler Thromb Vasc Biol. 2007;27:2292-2301.

8. Erdmann J, Grosshennig A, Braund PS, et al. New susceptibility locus for coronary artery disease on chromosome 3q22.3. Nat Genet. 2009;41:280-282.

9. O'Donnell CJ, Kavousi M, Smith AV, et al. Genome-wide association study for coronary artery calcification with follow-up in myocardial infarction. Circulation. 2011;124:2855-2864.

10. Ellis $\mathrm{KL}$, Frampton $\mathrm{CM}$, Pilbrow AP, et al. Genomic risk variants at $1 p 13.3,1 q 41$, and $3 q 22.3$ are associated with subsequent cardiovascular outcomes in healthy controls and in established coronary artery disease. Circ Cardiovasc Genet. 2011;4:636-646.

11. Alshahid M, Wakil SM, Al-Najai M, et al. New susceptibility locus for obesity and dyslipidaemia on chromosome 3q22.3. Hum Genomics. 2013;7:15.

12. Hubacek JA, Vrablik M, Dlouha D, et al. Gene variants at FTO, 9p21, and $2 q 36.3$ are age-independently associated with myocardial infarction in Czech men. Clin Chim Acta. 2016;454:119-123.

13. Hubacek JA, Staněk V, Gebauerová $M$, et al. Association between a marker on chromosome 9 and acute coronary syndrome: Confirmatory study on Czech population. Folia Biol (Praha). 2012;58:203-208.

14. Hubacek JA, Staněk V, Gebauerová M, et al. Rs6922269 marker at the MTHFD1L gene predict cardiovascular mortality in males after acute coronary syndrome. Mol Biol Rep. 2015:42:1289-1293.

15. Tunstall-Pedoe H, Kuulasmaa K, Tolonen H, Davidson M, Mendis S. MONICA monograph and multimedia sourcebook. World's largest study of heart disease, stroke, risk factors, and population trends 1979-2002. Geneva: World Health Organisation, 2003.

16. Hubacek JA, Lanska V, Adamkova V. Lack of an association between SNPs within the cholinergic receptor genes and smoking behavior in a Czech post-MONICA study. Genet Mol Biol. 2014;37:625-630.

17. Miller SA, Dykes DD, Polesky HF. A simple salting out procedure for DNA extraction from human nucleated cells. Nucleic Acid Res. 1988;16:1215.

18. Day IN, Humphries SE, Richards S, Norton D, Reid M. High-throughput genotyping using horizontal polyacrylamide gels with wells arranged for microplate array diagonal gel electrophoresis (MADGE). Biotechniques. 1995;19:830-835.

19. Hubáček JA, Pikhart $H$, Peasey A, Kubínová R, Bobák M. Nobody is perfect: Comparison of the accuracy of PCR-RFLP and KASP'M method for genotyping. ADH1B and FTO polymorphisms as examples. Folia Biol (Praha). 2015;61:156-160.

20. Palomaki GE, Melillo S, Bradley LA. Association between 9 p21 genomic markers and heart disease: A meta-analysis. JAMA. 2010;303:648-656.

21. Munir MS, Wang Z, Alahdab F, et al. The association of $9 p 21-3$ locus with coronary atherosclerosis: A systematic review and meta-analysis. BMC Med Genet. 2014;15:66.
22. Calkin AC, Tontonoz P. Genome-wide association studies identify new targets in cardiovascular disease. Sci Transl Med. 2010;2:48ps46.

23. Davignon J, Dubuc G, Seidah NG. The influence of PCSK9 polymorphisms on serum low-density lipoprotein cholesterol and risk of atherosclerosis. Curr Atheroscler Rep. 2010;12:308-315.

24. Haas U, Sczakiel G, Laufer SD. MicroRNA-mediated regulation of gene expression is affected by disease-associated SNPs within the 3'-UTR via altered RNA structure. RNA Biol. 2012;9:924-937.

25. van Rooij E, Sutherland LB, Liu N, et al. A signature pattern of stressresponsive microRNAs that can evoke cardiac hypertrophy and heart failure. Proc Natl Acad Sci USA. 2006;103:18255-18260. 